\title{
Effect of Silver Nano-Particles on Structural, Optical and Electrical Properties of Casted (Polyvinyl alcohol/ Polyacrylamide/Polyethylene oxide) Composites for Antibacterial Applications
}

khalid Abass ( $\square$ pure.khalid.haneen@uobabylon.edu.iq )

University of Babylon

Karar Abdali 0

University of Babylon

\section{Research Article}

Keywords: PEO, Nanosilver, nanoparticles, AC conductivity, Antibacterial

Posted Date: March 19th, 2021

DOI: https://doi.org/10.21203/rs.3.rs-324880/v1

License: (c) (1) This work is licensed under a Creative Commons Attribution 4.0 International License.

Read Full License 


\section{Abstract}

The (PVA-PAAm-PEO) weight percentage blends with Ag nanoparticles as a nanocomposites (NCs) have been prepared by solution casting method. Optical microscope and SEM were used to investigated the diffusion of nanoparticles (NPs) in the blends. NPs agglomeration were clearly appears in the high weight additives. The materials have been diagnosed by optical microscopy, SEM and FTIR. The absorption spectrum records in the wavelength scope (190-1100) $\mathrm{nm}$. The optical properties directly proportional with Ag nanoparticle additives except the transmittance and the energy gap were decreased. The optical parameters show that Ag doping clearly effects on the films characteristics, the optical constants enhanced. The AC electrical conductivity also calculated. This results can be applied in coatings for photographic films. The results applied as anti-bacterial to E-coli bacteria with the used additives of $\mathrm{Ag}$ (20-30 nm) NPs. The antibacterial effect of the prepared films also tested to be accompaniment with other applications.

\section{Full Text}

Due to technical limitations, full-text HTML conversion of this manuscript could not be completed. However, the manuscript can be downloaded and accessed as a PDF.

\section{Figures}
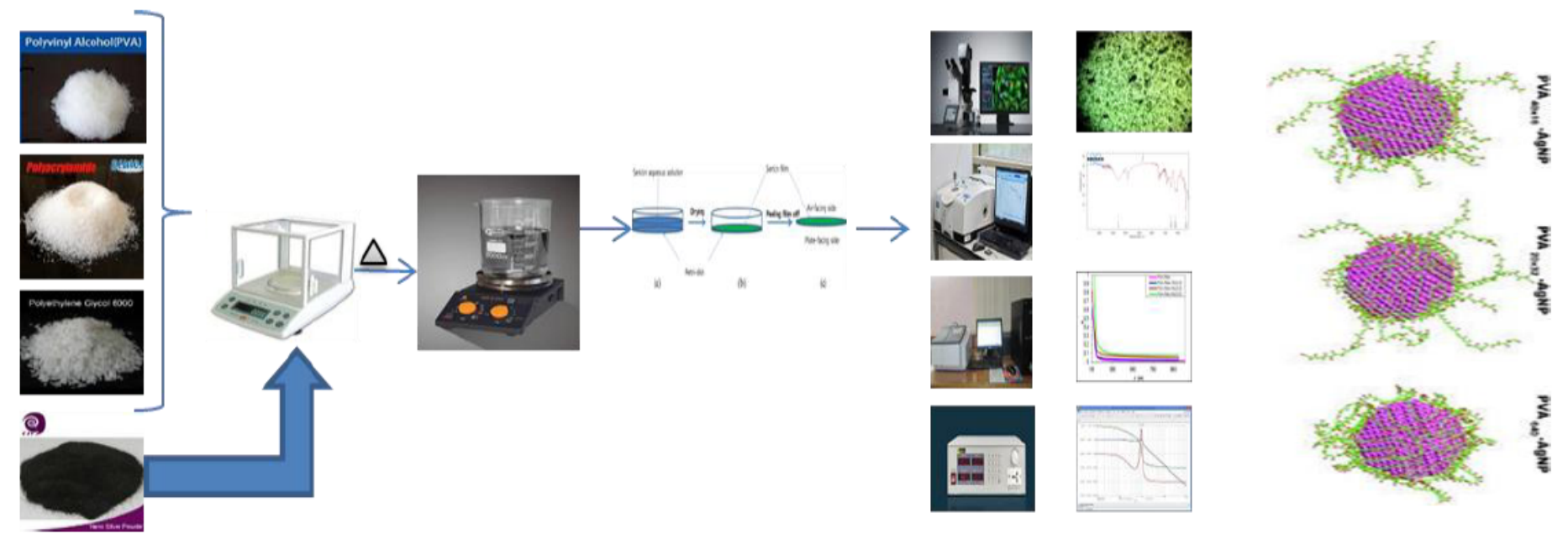

\section{Figure 1}

The practical diagram 


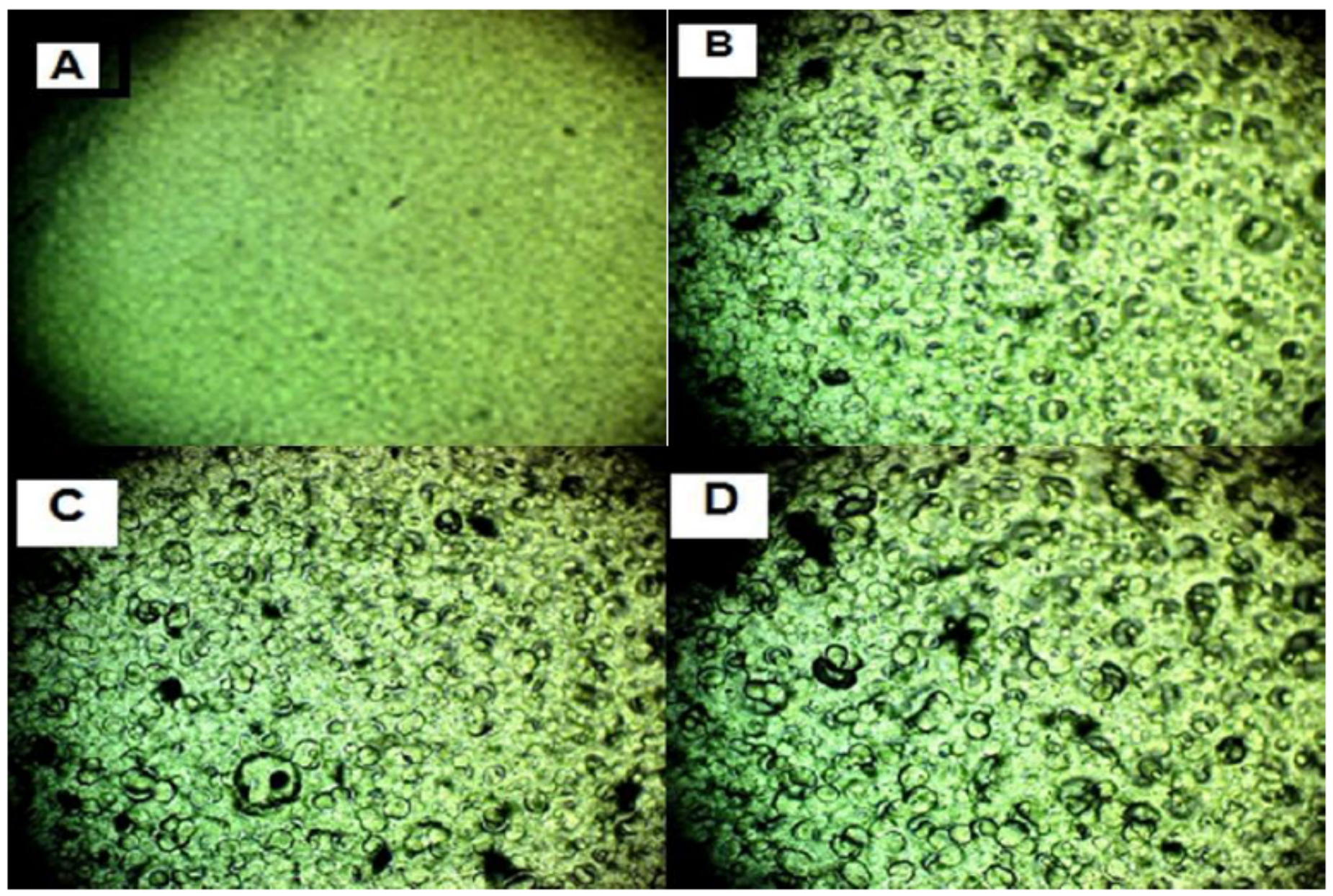

Figure 2

Photomicrographs (100X) of nanocomposites: A) PVA-PAAm-PEO, B) PVA-PAAm-PEO:0.02wt.\% Ag NPs, C) PVA-PAAm-PEO:0.04wt.\% Ag NPs, and D) PVA-PAAm-PEO:0.06wt.\% Ag NPs.

\begin{tabular}{|c|c|c|c|c|c|c|c|}
\hline SEM MAG: $25.0 \mathrm{kX}$ & Det: se & Lان & MIRA3 TESCAN & SEM MAG: $25.0 \mathrm{kK}$ & Det: se & 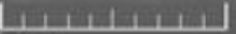 & MIRAS TESCAN \\
\hline WO: $11.51 \mathrm{~mm}$ & Bit: 10.00 & $2 \mu \mathrm{m}$ & & WD: $11.51 \mathrm{~mm}$ & Bi: 10.00 & $2 \mu m$ & \\
\hline View field: $8.30 \mu \mathrm{m}$ & Date(m/aly): 01/24/21 & & & View neld: $8.30 \mu \mathrm{m}$ & Date(m/ay): 01/24/21 & & \\
\hline
\end{tabular}


SEM photomicrographs of A) PVA-PAAm-PEO, B) PVA-PAAm-PEO:0.04wt.\% Ag NPs

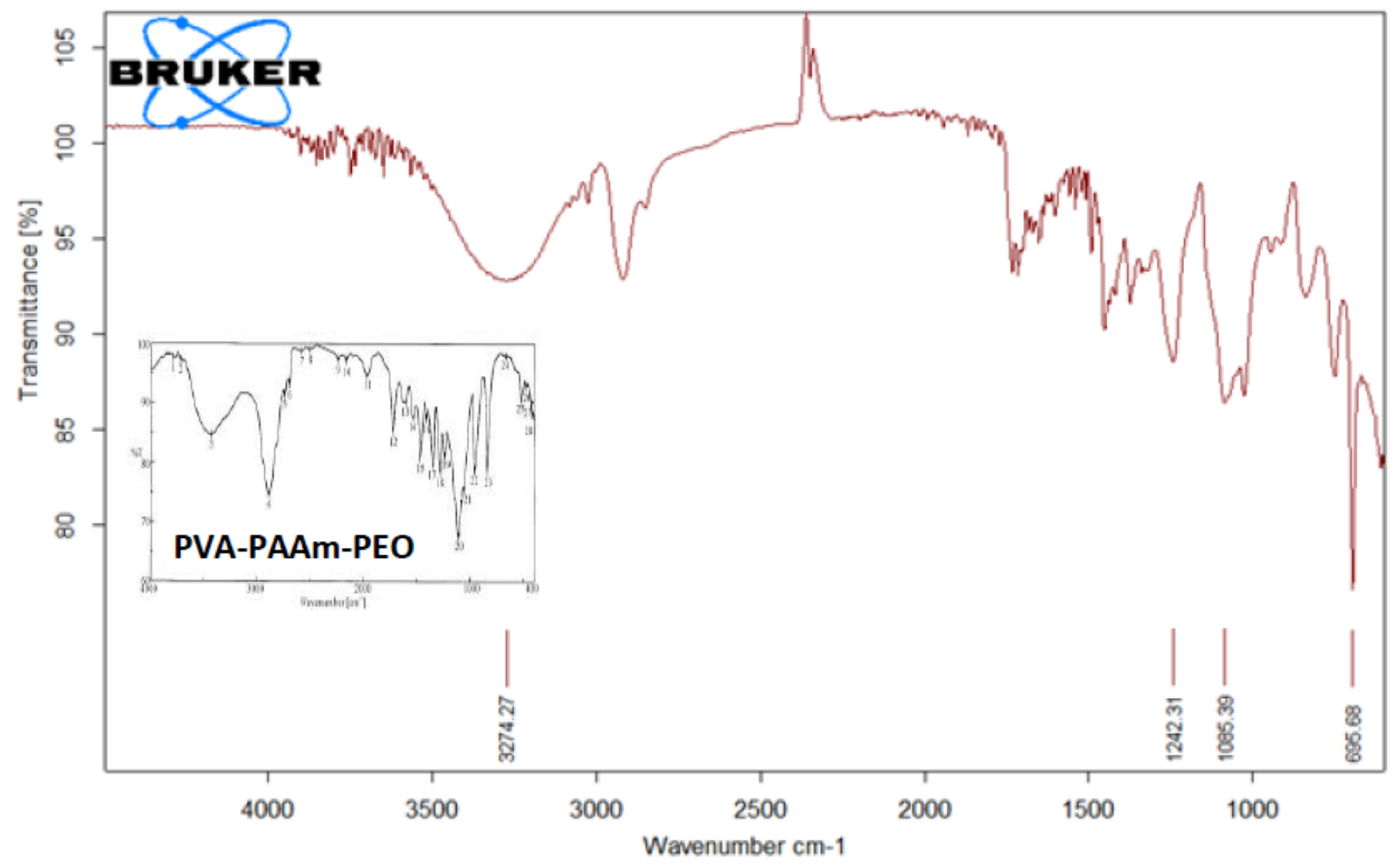

Figure 4

FTIR spectrum of (PVA-PAAm-PEO):0.04wt.\% Ag NC.
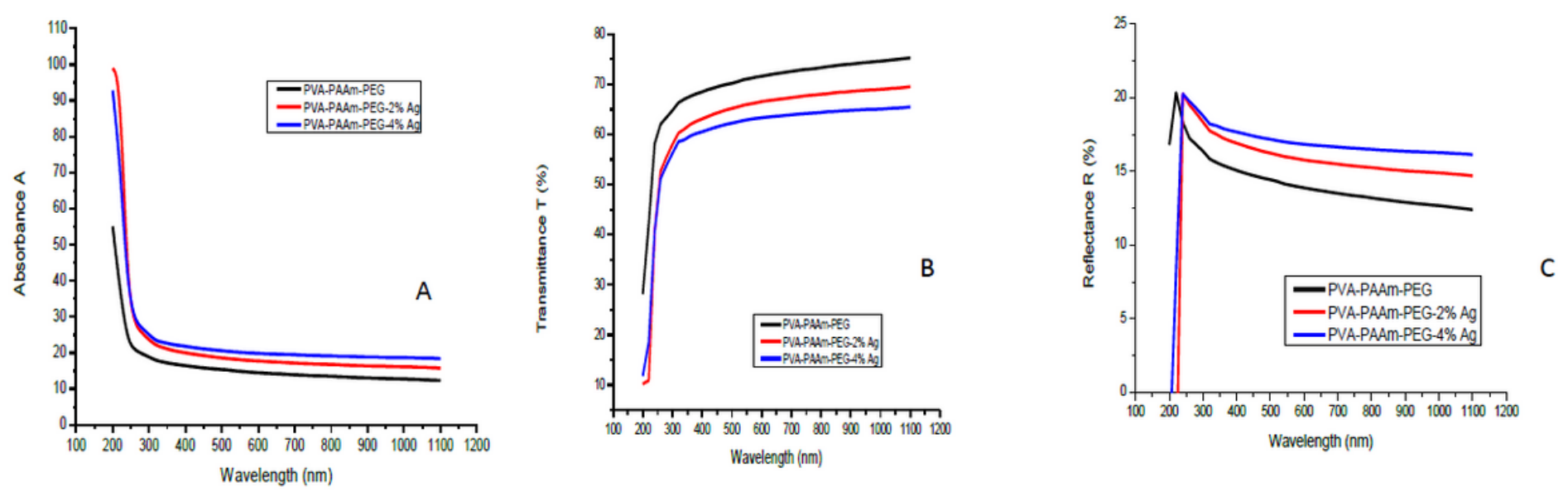

Figure 5

A) Absorbance vs. wavelength of PVA-PAAm-PEO-Ag nanocomposites. B) Transmittance vs. wavelength of PVA-PAAm-PEO-Ag nanocomposites, C) Reflectance vs. wavelength of PVA-PAAm-PEO-Ag nanocomposites. 

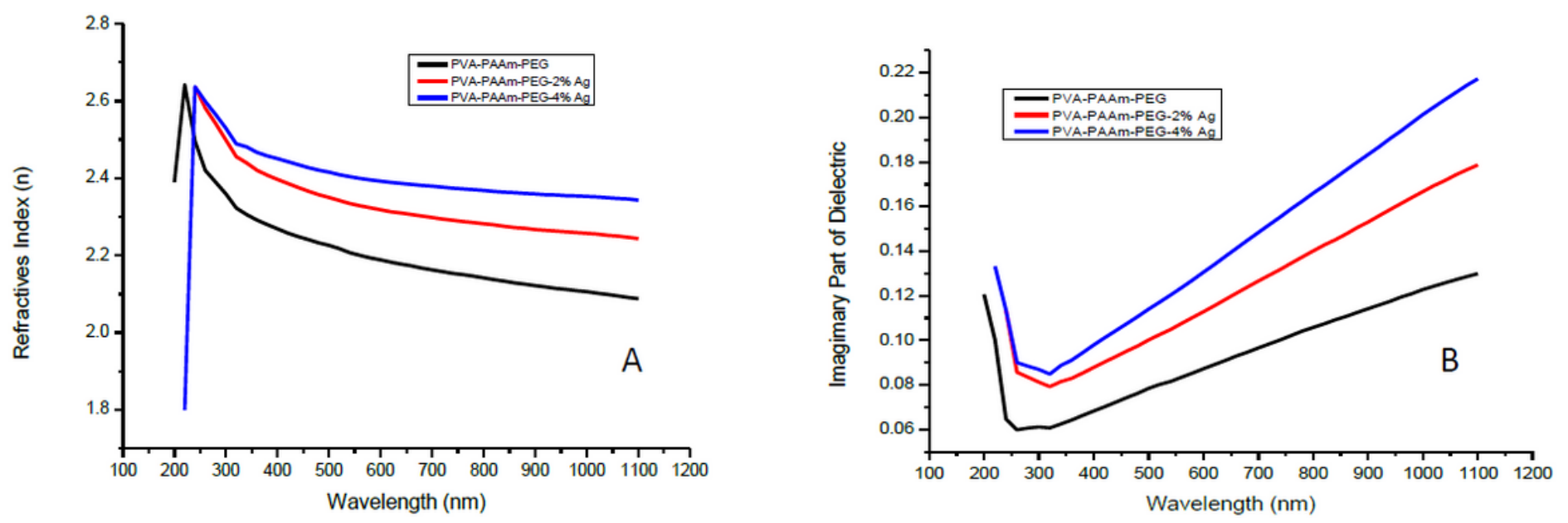

Figure 6

The refractive index vs. wavelength of PVA-PAAm-PEO-Ag nanocomposites, A) Real part of RI , B) Imaginary part of RI.

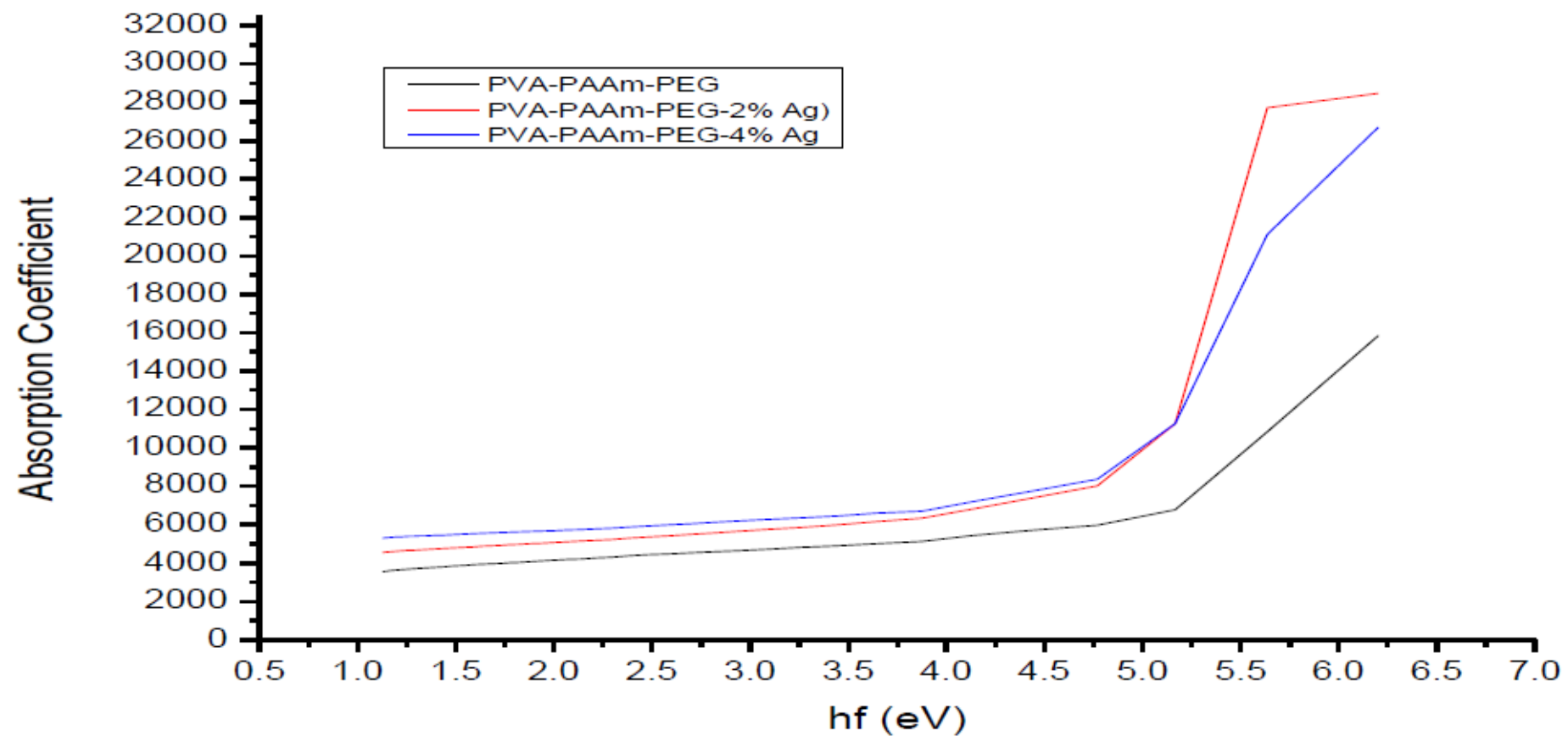

Figure 7

The absorption coefficient spectrum vs. wavelength of PVA-PAAm-PEO-Ag nanocomposites. 


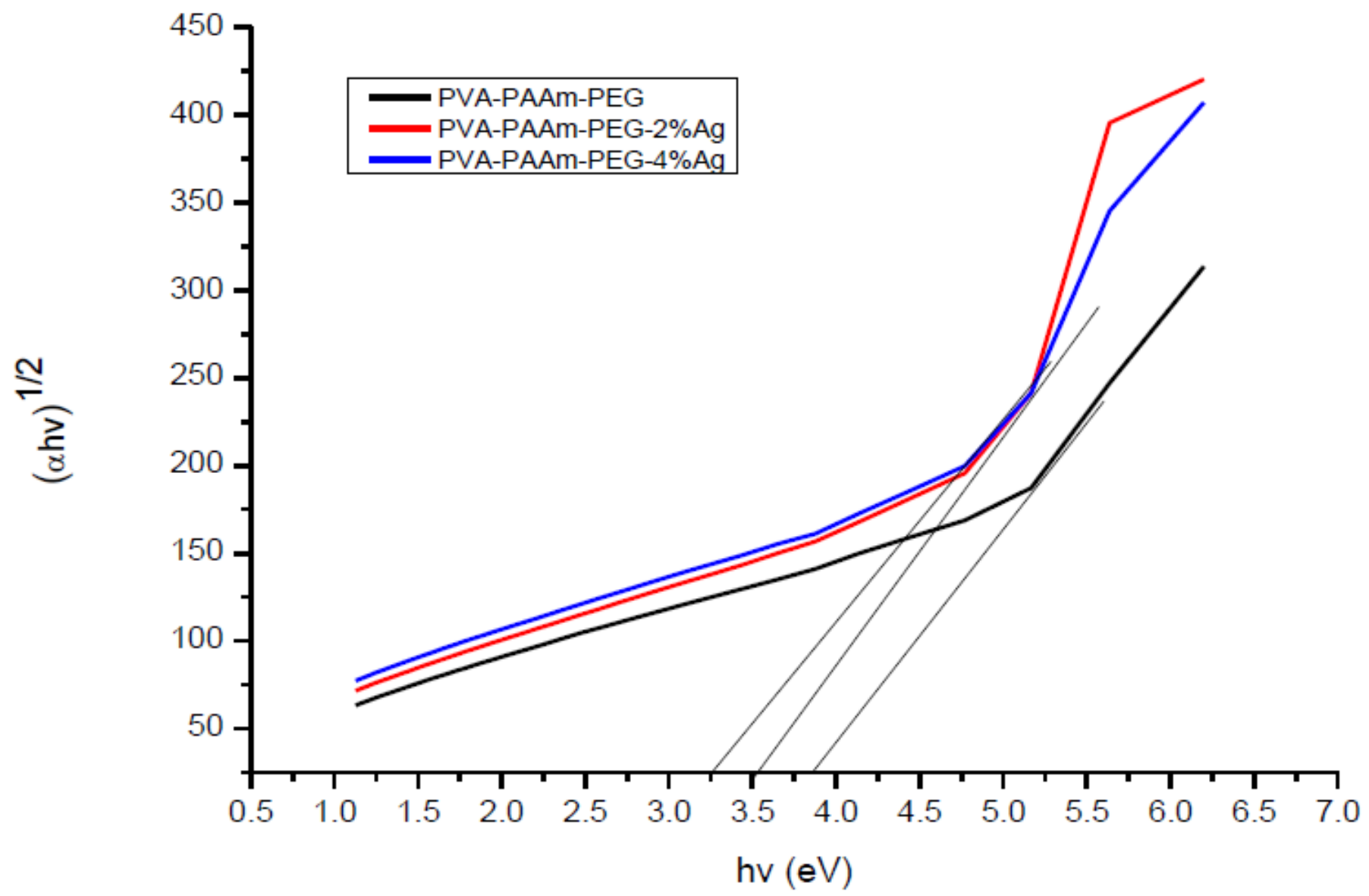

Figure 8

A plots of (ahv) $1 / 2$ vs. photon energy (hv) of PVA-PAAm-PEO-Ag nanocomposites. 


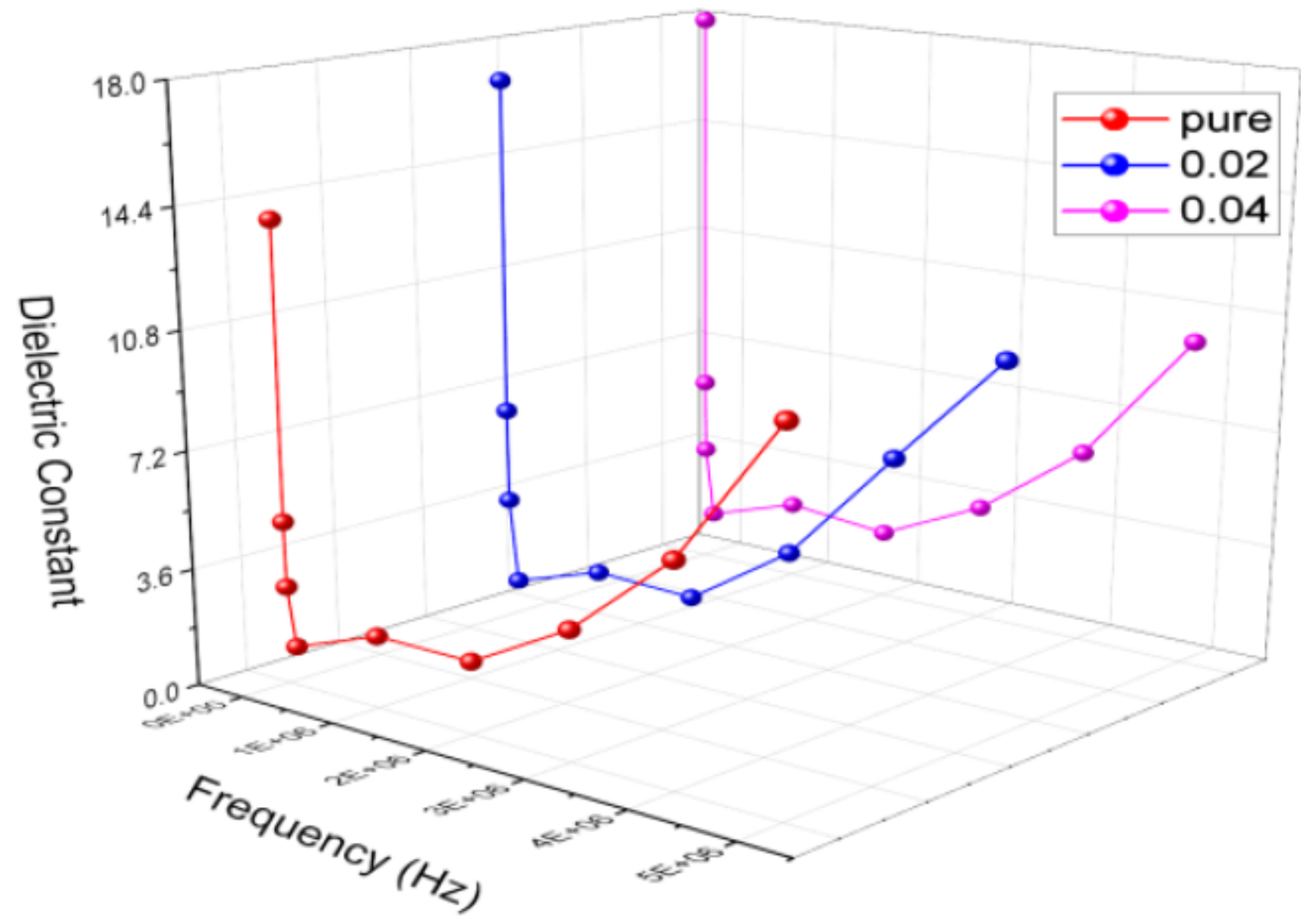

Figure 9

The dielectric constant vs. frequency of PVA-PAAm-PEO-Ag NCs.

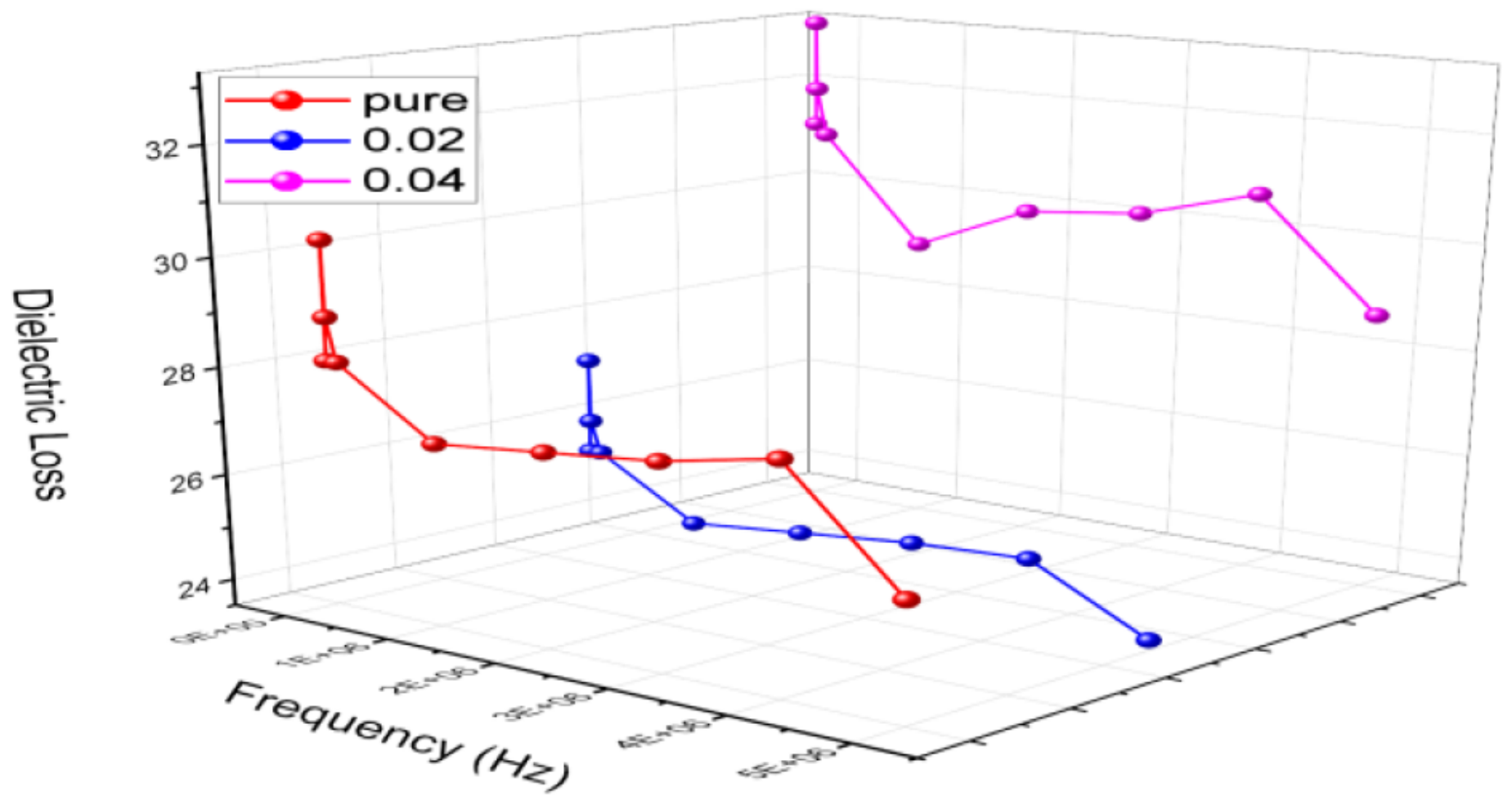


Figure 10

The dielectric loss vs. frequency of PVA-PAAm-PEO-Ag NCs.

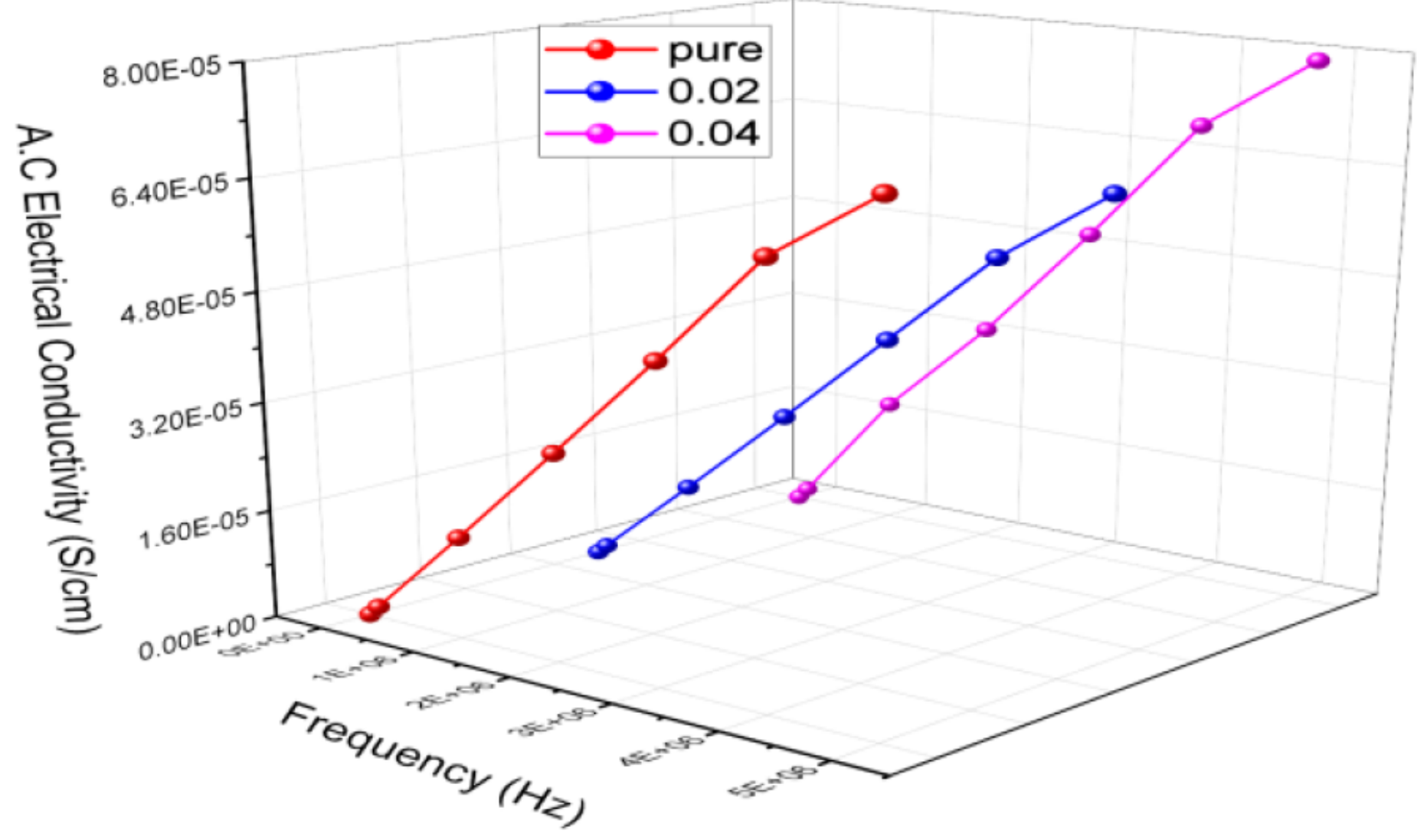

Figure 11

The A.C. electrical conductivity vs. frequency of PVA-PAAm-PEO-Ag NCs. 


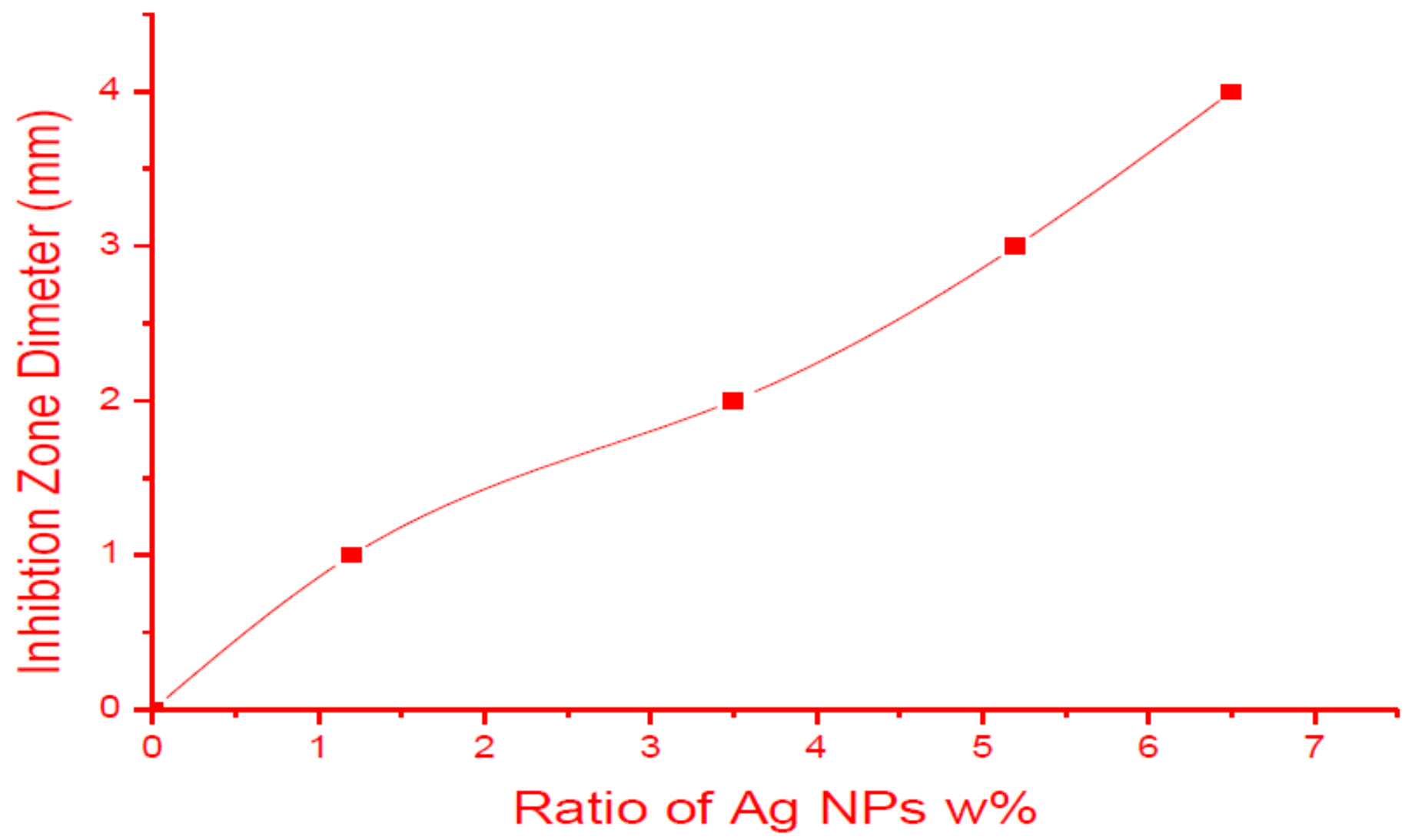

Figure 12

The inhibition zone diameter with Ag NPs weight percentage versus E. coli for PVA-PAAm-PEO-Ag NCs. 